\title{
Congenital Cystic Adenomatoid Malformation of the Left Lower Lobe with Compression of the Remaining Lung Tissue in a Newborn
}

\author{
BERNARD J. LEININGER, CAMERON HAIGHT *
}

\section{Case Description}

A white newborn girl, born after an uncomplicated full-term pregnancy and a normal delivery, was well developed, weighed $9 \mathrm{lb} 14 \mathrm{oz}$ and measured $55 \mathrm{~cm}$, but was breathing rapidly. Her blood pressure was $105 / 60$, pulse $120 / \mathrm{min}$ and regular, respirations $104 / \mathrm{min}$ and shallow, and body temperature 97.4

Her thorax was asymmetric, the left hemithorax being larger than the right. The right chest was dull to percussion; the left chest had good resonance. Breath sounds over the left chest were diminished. The cardiac dullness area extended from the sternum to the right anterior axillary line. Heart sounds were normal. The liver was palpable three centimeters below the right costal margin. The infant moved all extremities and cried vigorously.

Radiographic Studies. Roentgenograms of the chest showed a marked shift of the mediastinum to the right with a mottled, diffuse "cob-webbed" appearance of the left hemithorax. A barium swallow showed a normal esophagus and stomach, with the stomach and small bowel in a normal position below the left hemidiaphragm.

An angiocardiogram showed the branches of the pulmonary artery to the left lower lobe to be abnormal, the vessel pattern suggesting multiple displacements by intervening masses. Branches of the pulmonary artery to the left upper lobe appeared to have a normal pattern. The left pulmonary veins pursued a tortuous course but eventually drained into the left atrium. The branches of the right pulmonary artery were decreased in caliber, apparently because of compression by an overextended left lung. Circulation through the lungs was slow, especially on the right where the pulmonary arteries were markedly opacified. The chambers of the heart and the great vessels, although displaced, appeared normal.

Laboratory Determinations. The hemoglobin level was 21.7 grams and the white blood count

Division of Thoracic Surgery, University of Michigan School of Medicine, Ann Arbor, Mich.

Correspondence to Bernard J. Leininger, 55 East Washington Street, Chicago, IIl. 60602.

* Deceased. was 14,650 . Serum electrolytes were within normal limits.

Clinical Course. From the moment of birth, the infant was dyspneic and had peripheral cyanosis. The respiratory distress increased during the first 24 hours, and it became necessary to support the breathing of the infant by means of an endotracheal tube and a mechanical respirator. Angiocardiogram was performed to rule out a right to left shunt or agenesis of the right lung. Because the infant's condition was deteriorating, surgical decompression of the right lung and mediastinum by what appeared to be an overdistended left lung seemed advisable.

Operative Procedure. On the third day of life, a left thoracotomy was performed through the fifth intercostal space. The lower lobe appeared to fill the entire left hemithorax. Its surface was beefy red and nodular with multiple cystic areas varying from one millimeter to approximately onc centimeter in size. A small pink hypoplastic-appearing left upper lobe was seen above the distended lower lobe. Upon manipulation of the lung, the involved lobe was noted to expand further. After excision of the left lower lobe, the upper lobe did not expand well. Approximately $250 \mathrm{ml}$ of air was evacuated from a right pneumothorax. The right lung would not expand sufficiently to fill the hemithorax and appeared hypoplastic. In order to maintain peripheral oxygenation, 35 to $40 \mathrm{~cm}$ of water pressure was applied to the ventilatory bag. Throughout the procedure, the respiratory function did not appear to change significantly. Two small catheters were used to drain the left pleural space and a third was placed in the right pleural space across the mediastinum and brought out through the anterior left chest, with all tubes connected to underwater seal drainage bottles and suction. The infant tolerated the operative procedure fairly well. An immediate postoperative film of the chest showed that neither the right lung nor the left upper lobe had expanded in the anticipated fashion.

Postoperative Course. The endotracheal tube was left in place as it was again necessary to ventilate the child with a mechanical respirator. A postoperative film of the chest taken 15 hours after operation showed some expansion of the right 


\section{CYSTIC MALFORMATION OF LUNG}

lung. Postoperatively, the infant's difficulties seemed to be related to respiratory insufficiency. Increased ventilatory pressures were required to provide adequate ventilation. Death from respiratory insufficiency occurred 26 hours after operation.

Autopsy. The pertinent postmortem findings were in the thorax. Approximately $10 \mathrm{ml}$ of serous fluid were in each pleural cavity. The left upper lobe was atelectatic and when cut had a meaty consistency. It measured $6.5 \times 3.5 \times 2 \mathrm{~cm}$ and weighed $11 \mathrm{gm}$. All three lobes of the right lung had patchy areas of atelectasis. The right lung measured $7 \times 6 \times 2 \mathrm{~cm}$ and weighed $36 \mathrm{gm}$.

On microscopic examination, both lungs showed moderate hyaline membrane formation, with squamous cells and eosinophilic granular material in the alveoli, and intra- and interalveolar focal hemorrhages.

The previously resected left lower lobe was bulky and heavy, with a rubbery consistency. Its surface was red and bosselated. Its substance contained numerous cysts ranging from one to six $\mathrm{mm}$ in diameter; some of these were empty and others contained clear serous fluid. The excised lobe weighed $87.5 \mathrm{gm}$ and measured $10.5 \times 7 \times 5 \mathrm{~cm}$. Microscopic examination showed numerous cysts lined by terminal bronchioles. The decrease in bronchial cartilage, tubular glands, and alveolar differentiation was marked. Areas of increased loose connective tissue containing scattered lymph. ocytes, histiocytes, capillaries, and smooth muscle were seen in addition to foci of alveolar hemorrhage. The bronchioles contained aspirated squamous and granular debris. The diagnosis by the Department of Pathology was congenital cystic adenomatoid malformation of the lung.

\section{Discussion}

Sixteen of the 47 patients with congenital cystic adenomatoid malformation of the lung reported in the literature ${ }^{1}$ have undergone resection, with 14 survivals. The remaining 31 cases who did not undergo surgery were diagnosed at necropsy. This condition has been described only in infants most of whom were stillbirths or who died within a few days after birth. ${ }^{2-5}$

Clinically, this lung malformation usually shows itself first as respiratory distress which begins within the first few hours or days after birth. A high percentage of the cases described in necropsy reports have been stillborns and premature infants, suggesting intrauterine difficulties. The possibility of intrauterine distress has been discussed by Ch'In, ${ }^{2}$ who suggested that the enlarged lung caused mechanical compression of the mediastinum

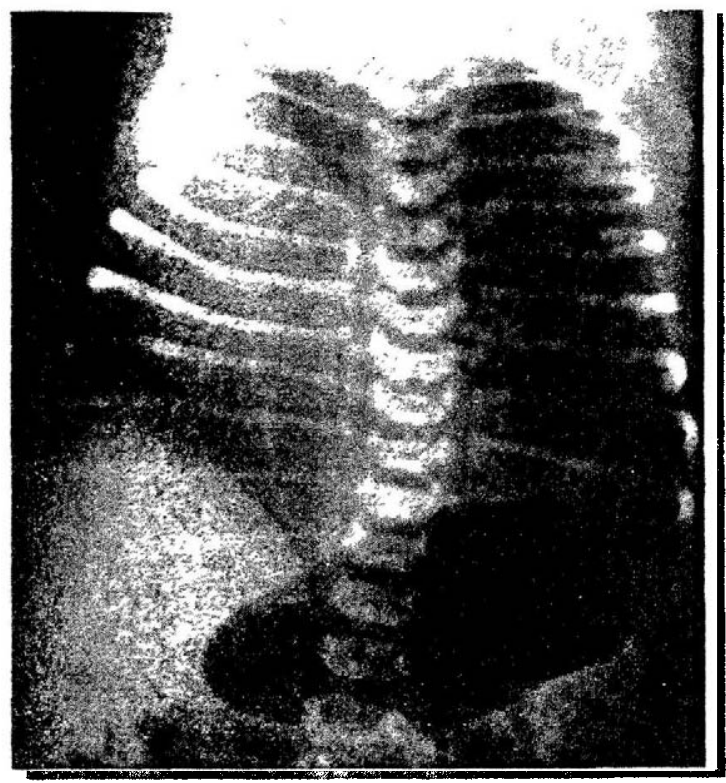

Fig. 1. Roentgenogram taken shortly after birth showing the mottled, diffuse "cob-webbed" appearance of the left hemithorax with the displacement of the mediastinal structures to the right.

leading to congestive heart failure and anasarca. This sequence caused the fetus to become ill or die, and this in turn led to premature delivery. Hence the high incidence

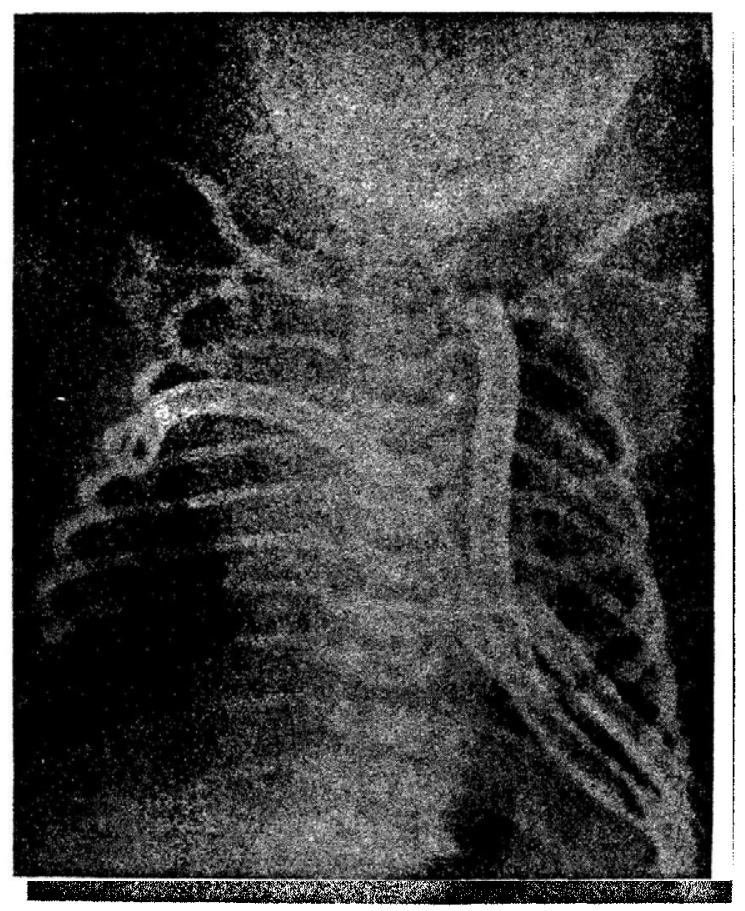

Fic. 2. Postoperative roentgenogram showing failure of the right lung and the left upper lobe to expand. 


\section{LEININGER AND HAIGHT}

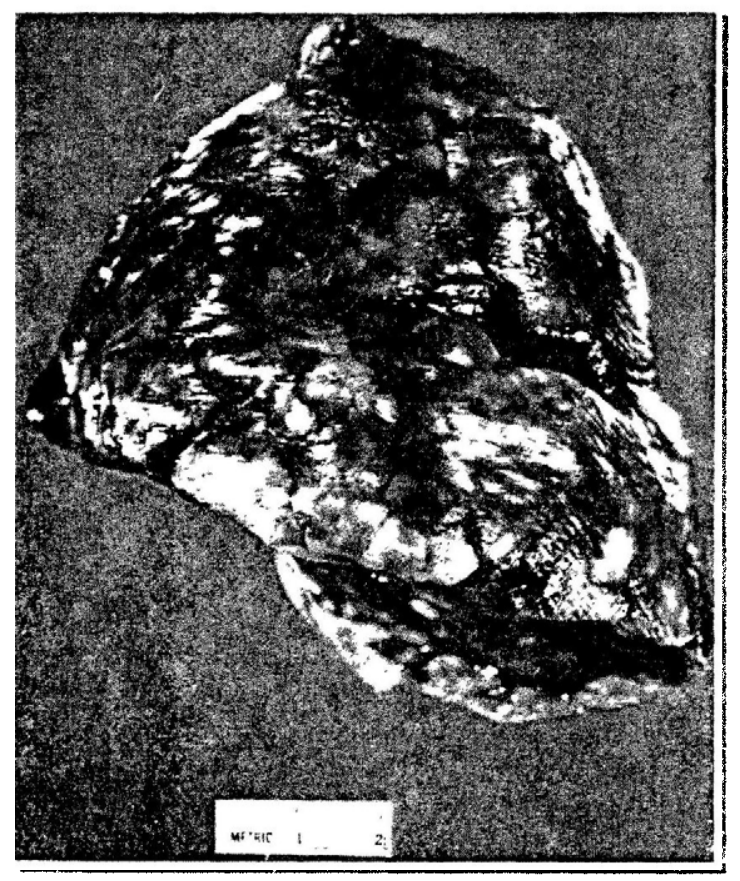

FIc. 3A. The external appearance of the resected left lower lobe.

of stillbirth and prematurity alluded to by others. ${ }^{6,}$ ?

Congenital lobar emphysema enters the differential diagnosis. This condition is quite similar in its diagnostic, clinical, and pathologic aspects, except that the symptoms, in general, begin later in the newborn period..$^{8-11}$ Both disorders cause respiratory embarrassment through overexpansion of the involved lung and compression of the remaining lung. Roentgenograms of the chest show displacement of the mediastinum to the opposite side. A distinguishing feature of adenomatoid malformation is the mottled, granular appearance of the lung, interspersed with scattered areas of cystic radiolucency. ${ }^{12}$ In contrast, the $x$-ray appearance of congenital lobar emphysema is more diffusely radiolucent, more apt to be confused with acquired or congenital cysts of the lung. ${ }^{13}$ The diagnosis in our patient was suggested by the radiologist before the operation was done.

Fluoroscopy with attention to the diaphragm and the mediastinum may be helpful. The fluoroscopic findings in congenital cystic adenomatoid malformation of the lung are similar to those of congenital lobar emphy- sema, but different from atelectasis or hypoplasia of one lung with compensatory emphysema of the contralateral lung. With atelectasis or hypoplasia, the diaphragm on that side will be elevated, whereas, with congenital lobar emphysema or adenomatoid malformation, the diaphragm on the affected side is depressed, and the mediastinum will shift toward the unaffected side on expiration.

A study of the gastrointestinal tract using contrast material will help to rule out a diaphragmatic hernia with bowel residing in the thorax. ${ }^{12}$

The pulmonary arteriogram which was performed in our patient preoperatively showed compressed narrow pulmonary vessels with slow circulation through the lungs. This strongly suggested a structural abnormality such as hypoplasia.

The object of surgical intervention in these infants $^{1.2}$ is to remove the space-occupying mass so that the remaining lung can expand,

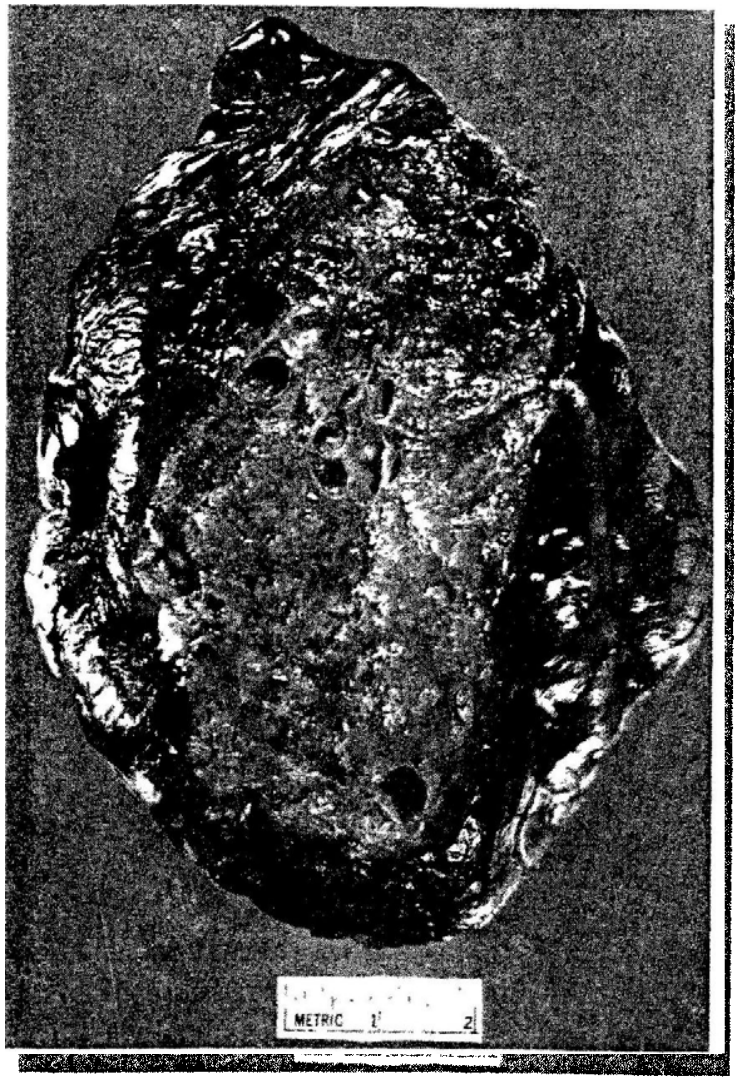

Frr. 3B. Cut section of the left lower lobe showing the multicystic spaces. 


\section{CYSTIC MALFORMATION OF LUNG}

and to alleviate any compression of the heart or other mediastinal structures. The anesthesiologist's inability to ventilate our patient with increased ease after the thorax had been decompressed caused concern. In order to sustain vemtilation sufficient for tisstue oxygenation and to maintain vital signs, 30 to 40 cm of water pressure was needed.

The preoperative use of the mechanical respirator in patients with congenital cystic adenomatoid malformation of the lung or congenital lobar emphysema is fraught with danger. This increased pressure upon the abnormal lung may compound hyperinflation. There is danger also of rupturing one of the cysts with the production of tension pneumothorax. Hence one must be extremely careful when administering anesthesia to these infants. Many anesthesiologists prefer not to apply positive pressure until the thorax is opened and can be decompressed. The preoperative use of positive pressure ventilation in this case was one of necessity. The infant was improved by the use of a mechanical respirator and could not get along without it. Postoperatively it was again necessary to use the ventilator. It was our plan to support the baby's respirations in the hope that the remaining lung would expand, but this did not happen and death was the result of respiratory insufficiency.

\section{Clinical Pathologic Correlations}

Our inability to expand the lungs and to adequately ventilate the infant described above could well be analogous to the mechanical compression of the lung which occurs in congenital diaphragmatic hernia. These hernias are frequently accompanied by atelectasis of the lung on the hernia side. This atelectatic lung may appear at the time of surgery to be hypoplastic or even rudimentary, but clinical experience has shown that such a lung will expand and become normal in appearance and function within one to five days. ${ }^{14}$

The in utero compression of the lung affected with congenital cystic adenomatoid malformation may be considerable. This is suggested by both the large number of stillbirths and the frequency of the respiratory

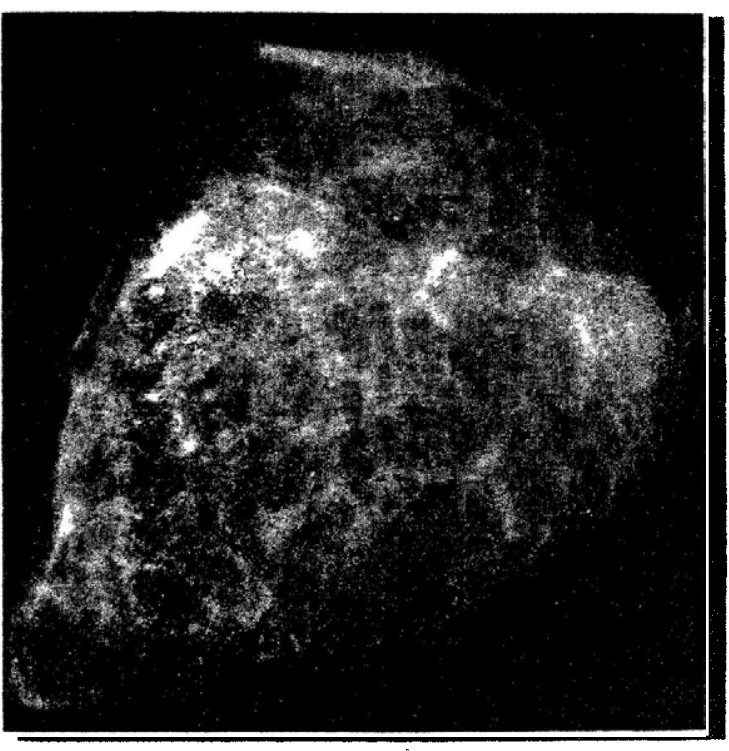

Fis. 36 . X-ray of the inflated resected left lower lobx showing the irregular radiodensities.

distress which occurs in the immediate postnatal period.

The lung of an infant that has been compressed in utero represents a different clinical entity from atelectasis occurring in a previously expanded lung. The latter, after reexpanding, will again function as a nomal lung, whereas the former requires a period (one to five days) to expand and function normally. In reported series ${ }^{14.15}$ of infants with congenital diaphragmatic hernia, a compressed lung that does not promptly ex-

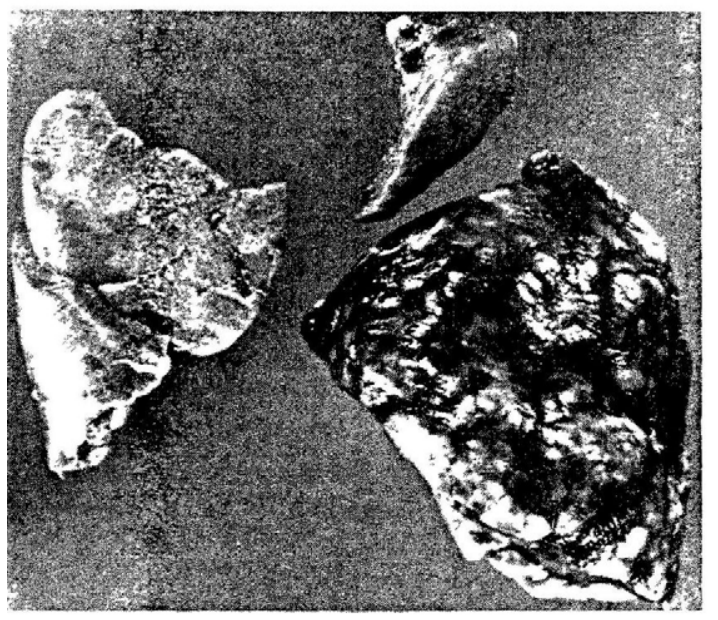

Fic, 4. Comparison of the relative sizes of the right lung, left upper lobe, and left lower lobe was possible at autopsy 


\section{LEININGER AND HAIGHT}

pand carries a grave prognosis. Cerilli ${ }^{14}$ has commented that three of the eight deaths in his series of patients with congenital diaphragmatic hernia had lung hypoplasia; however, the pathologic findings in these cases were not described. This is mentioned inasmuch as there seems to be a disparity between the clinical and pathologic criteria for diagnosis of hypoplasia of the lung. The appearance and function may suggest an underdeveloped lung, but pathologic examination may show normal structures not fully aerated.

The contralateral lung of an infant with a congenital diaphragmatic hernia is normal and hence sufficient to support the patient. Morphologically, the congenitally compressed lung has normal appearing structures and is not a hypoplastic lung, yet it is incapable. of carrying out the functions of a lung until it has had the opportunity to gradually expand.

In retrospect, we believe the pulmonary insufficiency displayed by our infant was the result of mechanical compression of the lung beginning in utero. This otherwise normal tissue was unable to sustain the necessary pulmonary functions in the extrauterine environment.

\section{References}

1. Merenstein, G. B.: Congenital cystic adenomatoid malformation of the lung. Report of a case and review of the literature. Am. J. Dis. Child 118: $772,1969$.
2. Ch'In, K. Y. and Tang, M. Y.: Congenital adenomatoid malformation of one lobe of a lung with general anasarca. Arch. Pathol. 48: 221, 1949.

3. Belanger, Raymond, LaFleche, L. R. and Picard, Jean-Louis: Congenital cystic adenomatoid malformation of the lung. Thorax 19: 1, 1964.

4. Bain, G. O.: Congenital adenomatoid malformation of the lung. Dis. Chest 36:430, 1959.

5. Breckenridge, R. L., Rehermann, R. L. and Gibson, E. T.: Congenital cystic adenomatoid malformation of the lung. J. Pediatr. 67: 863, 1965.

6. Avery, Mary E.: The Lung and Its Disorders in the Newborn Infant. Philadelphia, W. B. Saunders Company, 1964, p. 74.

7. Gottschalk, W. and Abramson, D.: Placental edema and fetal hydrops. A case of congenital cystic and adenomatoid malformation of the lung. Obstet. Gynecol. 10: 626, 1957.

8. Fischer, H. D. et al.: Lobar emphysema in infants and children. J. Pediatr. 41: 403, 1952.

9. Jones, J. C., Almong, C., Meyers, B. W., Snyder, H. M. and Patrick, J.: Lobar emphysema and congenital heart disease in infancy. $J$. Thorac. Cardiovasc. Surg. 49: 1, 1965.

10. Mandelbaum, I., Heimburger, I. and Battersby, J. S.: Congenital lobar obstructive emphysema: report of 8 cases and literature review. Ann. Surg. 162: $1075,1965$.

11. Sloan, H.: Lobar obstructive emphysema in infancy treated by lobectomy. J. Thorac. Cardio. vasc. Surg. 26: 1, 1953.

12. Craig, J. M., Kirkpatrick, J. and Neuhauser, E. B. D.: Congenital cystic adenomatoid malformation of the lung in infants. Am. J. Roentgenol. Radium Ther. Nucl. Med. 76: 516, 1956.

13. Ravich, M. M. and Hardy, J. B.: Congenital cystic disease of the lung in infants and children. Arch. Surg. 59: 1, 1949.

14. Cerilli, G. James: Foramen of Bochdalek hernia, a review of the experience at Children's Hospital of Denver, Colorado. Ann. Surg. 159: 385, 1964. 